\title{
Strategic power in the European Union:
}

\section{Evaluating the distribution of power in policy games}

\author{
by \\ Bernard Steunenberg $^{\mathrm{a}}$, Dieter Schmidtchen ${ }^{\mathrm{b}}$, and Christian Koboldt ${ }^{\mathrm{c}}$ \\ version: September 29, 1998 (WP280995.wpd)
}

\begin{abstract}
In this paper we propose a new method to evaluate the distribution of power between decision making bodies in the European Union. Conventional methods that measure the voting power of players, such as the Banzhaf, Johnston, Holler, and Shapley-Shubik indices, are insufficient for this purpose. They take no account, in an endogenous way, of the differences in the abilities of players to affect the outcome of decision making, which are a result of the existence of political institutions. We propose a different way to measure decision making power based on the distance between a player's ideal point and the equilibrium outcome of a game. While all previous indices are based on cooperative game theory, the index developed this paper is based on non-cooperative game theory, which has been the dominant thrust of theoretical politics and economics in the last years. The new index is applied to legislative procedures in the European Union.
\end{abstract}

keywords: strategic power index, voting power indices, non-cooperative game theory, political institutions, European Union

We thank Patrick Dunleavy, Martin van Hees, Ronald Heiner, Manfred Holler, Nicholas Miller, George Tsebelis and the Journal's anonymous referees for helpful comments and suggestions. The paper benefitted from discussions at seminars at the Charles University, Prague, Czech Republic, the Economics Department at the University of Leuven, Belgium, the Department of Sociology at the University of Groningen, the Netherlands, and the panel on 'Institutions and power in the European Union' of the 1997 Annual Meeting of the American Political Science Association, Washington DC, U.S.A.

a University of Twente, Faculty of Public Administration and Public Policy, Enschede, The Netherlands.

b Center for the Study of Law and Economics, University of Saarland, Saarbrïcken, Germany.

c London Economics Ltd., London, United Kingdom. 


\section{Introduction}

The enlargement of the European Union and the current constitutional debate about the institutions of the Union have led to a large number of studies that assess the voting power of member states. These studies have assessed the power of the member states in the Council of the European Union ${ }^{1}$ (Johnston and Hunt, 1977; Brams, 1985; Brams and Affuso, 1985; Hosli, 1993, 1994; Widgrén, 1994; Johnston, 1995; Berg and Lane, 1996; Nurmi, Meskanen and Pajala, 1996), the European Parliament (Taylor and Johnston, 1978; Fowler, Polhuis, and Paine, 1983; Lane, Maeland and Berg, 1995; Hosli, 1997), or both (Mattei, 1990; Peters, 1996; Lane, Maeland and Berg, 1996). Furthermore, a number of studies take note of the fact that these institutions are related in the decision making process. Such studies compute the voting power of member states by assuming that representatives in the various decision making bodies are motivated either by their 'national interest' or by ideology, and then subsequently add up their voting power in these different bodies (Hosli, 1995; Bindseil and Hantke, 1997; Colomer and Hosli, 1997). There are also a few studies that focus on the distribution of power between different decision making bodies in the Union (Nurmi and Meskanen, 1996; Bindseil and Hantke, 1997; Berg and Lane, 1997; Laruelle and Widgrén, 1997; Turnovec, 1997). These studies are part of a broader literature which evaluate the relative impact of actors in voting processes. Among the subjects addressed by this body of literature are the role of both houses in the U.S. Congress, the relationship between Congress and the president in the U.S. (Brams, 1989; Brams, Affuso, and Kilgour, 1989), voting in the United Nations Security Council (Brams, 1975: 182-190), and the role of provinces in the 1971 constitutional amendment in Canada (Miller, 1973).

These analyses employ well-established power indices, such as the Shapley-Shubik index (Shapley, 1953; Shapley and Shubik, 1954) and the (normalized) Banzhaf index (Banzhaf, 1965). These indices are

1 The Council of the European Union, or Council in this contribution, is frequently referred to as the Council of Ministers, and prior to 1994 its full official name was the Council of Ministers of the European Communities. It should not be confused with the European Council, which is the meeting of the Heads of State, or their foreign ministers, of the Union's member states. 
based on the presumption that players form 'winning' coalitions in order to reach some desired outcome. Their power--that is, the extent to which a player may affect the outcome of a vote--is conceived as the extent to which a player turns a losing coalition into a 'winning' coalition for all mathematically possible permutations of players (Shapley-Shubik index), or the relative number of times a player is decisive in a vote (Banzhaf index). These 'classical' indices have been supplemented with more recent power measures, such as the Johnston index (Johnston, 1978), the Deegan-Packel index (Deegan and Packel, 1979), and the Holler index (Holler, 1982, 1984). The main differences between these indices are the ways in which coalition members share the benefits of their cooperation, and the kind of coalition players choose to form (see Colomer, 1998). While the Banzhaf index and the Holler index characterize the benefits of cooperation as 'collective goods', which will be available to any coalition member in the same amount (for example, in terms of public policies), the Johnston and Deegan-Packel indices regard these benefits as 'individual goods', which will be equally divided among decisive members (for example, as cabinet portfolios or other special benefits). Moreover, the Banzhaf and Johnston indices are based on 'winning' coalitions, while the Deegan-Packel and Holler indices are determined by 'minimum winning' coalitions only. ${ }^{2}$

Garrett and Tsebelis recently criticized the conventional analyses of voting power in the context of the European Union because of their neglect of player preferences. ${ }^{3}$ By taking all 'winning' or 'minimum winning' coalitions into account, the voting power indices do not distinguish between feasible and nonfeasible coalitions. In their view, a coalition is non-feasible if a player exists that is not a member of a 'winning' coalition, while this player prefers the same points to the status quo as all coalition members (that is, the player's ideal point is found in the coalition's Pareto set with regard to the status quo). Since this player will support the same proposals as the coalition, there are no reasons to exclude this player from this

2 Colomer (1998) notes that the assumptions about the size of the coalition and the division of payoffs among coalition members can be incoherent. He suggests focusing only on nondominated coalitions in the case of indices that assume some division of payoffs (such as the Johnston index).

3 See Garrett and Tsebelis (1996), and Tsebelis and Garrett (1997). 
coalition. Moreover, Garrett and Tsebelis assume that the benefits of cooperation can best be typified as 'collective goods', so that the inclusion of an additional player will not reduce each player's share in the total payoff. They suggest computing a power index that is based on connected winning coalitions only, which has been proposed by others as well. ${ }^{4}$ However, Garrett and Tsebelis' approach has an important drawback, since they blur the distinction between 'power' and 'luck' (see Barry, 1980). A player may be 'lucky' in the sense that it is found in the coalition's Pareto set, while at the same time this player does not contribute to the existence of the coalition. Still they would regard this player as more 'powerful' than those that are not in the connected coalition.

A second point mentioned by Garrett and Tsebelis is that voting power indices do not take the Union's institutional structure seriously. Voting power indices are designed to evaluate a priori voting power of players in a setting that is not structured by any rules, except a voting rule. These indices, therefore, do not take account of other institutional aspects of the decision making process. However, voting does not take place in an institutional vacuum. Rules of order exist, which determine the type of proposals or amendments that can be made, and the agenda of the voting process that has to be used. Moreover, the voting body may use a committee structure, where committees-or subsets of voters-discuss and reformulate proposals before they are put to a final vote on the floor. Not only the vote as such, but also these structures determine the extent to which individual players are able to affect the outcome.

One way political institutions can be introduced is to add different weights to different players in the context of a weighted voting game (see, for instance, Kirman and Widgrén, 1995; Turnovec, 1997). Decision making will then be represented by one voting body in which players have voting weights that reflect their decision making rights. In case of the majority version of the consultation procedure in the Union, the Commission and the Council could be assumed to have weights such that a proposal can only be

4 See, for instance, Colomer (1998). 
adopted if it is supported by a coalition consisting of the Commission and a qualified majority in the Council, or a unanimous Council. However, the Commission is not just one member of a voting body, but has a monopoly over introducing legislative proposals (see also Tsebelis and Garrett, 1997: 18). Moreover, this method presumes that these weights are known in advance and can be determined exogenously. The problem of any such ex ante adjustment of voting weighs is that it does not explicitly deal with the strategic interaction of players within the context of a given set of rules. A more appropriate method would be to base the assessment of power on a model in which institutions have an endogenous effect on the behavior of players.

In addition, most power indices assume that all 'winning' coalitions have the same 'value' or total payoff in different institutional settings. These payoffs are either equal to all coalition members (for instance, in the normalized Banzhaf and Holler indices), or they are shared proportionally between coalition members (in the Johnston and Deegan-Packel indices, for instance). The constant-sum assumption is not satisfactory for analyses of different institutional arrangements since the total payoff between different arrangements is assumed to be the same. Only redistributions of payoffs may occur as one moves from one arrangement to another, since players are only able to capture different shares in the total payoff. This would make institutional change, i.e., the change from one set of rules to another, impossible, if such a change has to be based on the consent of most players. Varying total payoffs, which would allow for institutional change since most or all players may experience an improvement in their individual payoff, would be a more appropriate approach to the analysis of different institutional arrangements.

In this paper we propose a different method for measuring 'power', which is not based on the notion that players need to form some kind of majority coalition. Instead, our notion of 'power' is based on the average distance between players' ideal points and the equilibrium outcome in policy games where players have different abilities to affect the final outcome in view of the decision making procedure. Whereas voting power analyses are based on cooperative games, the method proposed in this paper employs the results of 
non-cooperative sequential games in which players decide on their actions at different stages. Actor preferences, as well as the rules of the decision making process, are fully integrated into the analysis. Since it allows players to act strategically, the index derived in the paper might be labeled the strategic power index.

For the first time major analytical tools are seriously applied to decision making in the European Union. We compare the strategic power of political actors in the Union, namely the Commission, the Council and the European Parliament. Our focus is on the division of power between the Union's main decision making bodies based on the structure of legislative decision making procedures. Modeling the interactions between these institutions as a sequential game, Steunenberg, Koboldt and Schmidtchen (1995) first studied the interbody division of power in the Union, based on the general approach developed in Steunenberg (1996). Whereas the focus of that paper has been on comitology, viz., the decision making rules that govern the implementation of legal acts (see also Steunenberg, Koboldt, and Schmidtchen, 1996, 1997), the present paper concentrates on legislative decision making. In addition, we compare our results based on the strategic power index with those of analyses using voting power indices.

The paper is organized as follows. Using a stylized example of decision making between the Commission and the Council, we show in Section 2 why voting power indices are unsatisfactory in evaluating the decision making power of players in sequential games. In Section 3 we introduce our alternative method to evaluate power, which is based on the recently developed theory of political institutions. In this section we propose the strategic power index, which is designed to evaluate the power of players in sequential spatial games. In Section 4 we present an application of the strategic power index to legislative decision making in the European Union. Section 5 concludes the paper.

\section{Limits of voting power indices}


To show why voting power indices do not represent the distribution of power between players in the European Union in a satisfactory and meaningful way, we start with a simple example. With regard to legislative decision making, the EC Treaty initially provided only for the unanimity version of the consultation procedure. This procedure allowed the Commission to propose new regulation or directives, which are subjected to unanimous consent by the Council. The latter implies that, in fact, each Council member has the right to veto the Commission's proposal. The European Parliament only needs to be consulted in this procedure. Since the Council can adopt a proposal whatever position Parliament takes, Parliament does not play a significant role and thus will not be discussed further.

Now assume that policies can be represented by a one-dimensional (left-right) outcome space, and players have Euclidean preferences. In addition, we assume that players have perfect and complete information. The Commission selects a proposal, which is then decided upon by the Council members. For our argument on the usefulness of voting power indices, we assume that Council members are not allowed to add new proposals to the agenda nor to amend the Commission proposal. The interactions between the Commission and Council members now resemble the well-known agenda setter model of Romer and Rosenthal (1978, 1979).

\section{[Diagram 1 about here]}

Diagram 1 presents a preference configuration that may occur for the Commission, which is conceived as a unitary actor, and a five member Council. In this diagram $V_{i}$ and $C$ denote the most preferred or ideal points of Council member $i$ and the Commission, respectively, and $V_{i}(q)$ stands for member $i$ 's point of indifference to the status quo $q$. The Commission, $C$, has a more progressive preference than most Council members, $V_{i}$. Nevertheless, the leftmost Council member, $V_{l}$, holds an even more extreme position. Given a status quo to the left of these players, the Commission will propose a measure that is equivalent to its own most preferred point. Since all Council members prefer this point to the status quo, the proposal will not be vetoed. So, in equilibrium, the outcome of this game is a legislative policy $x=C$. 
In this context, all players have to approve a measure, and no measure can be taken without the support of one of them. Each (last) player has the same probability of being pivotal, and each player is necessary to form the (minimum) winning coalition of all players. The Shapley-Shubik, Banzhaf, Johnston and Holler indices therefore allocate power values to each player of 1/6. Following Berg and Lane (1997) and Turnovec (1997), the aggregated score for the Council would be 5/6, which implies that the Council would be more powerful than the Commission. However, the abilities of these players to affect the equilibrium outcome differ. ${ }^{5}$ The Commission can take the initiative and draft a proposal, while Council members can only approve or reject this proposal. Council members may restrict the Commission's policy choice, but they cannot set the final proposal. The Commission enjoys discretion in choosing a new policy, which makes it more 'powerful' than the traditional indices indicate.

Adding together the scores of individual Council members to calculate the power of the Council leads to what we call an aggregation bias. This bias is due to the fact that, in inter-body analyses of voting power, the members of separate decision making bodies are treated as if they were the members of a single committee. However, in the game as discussed, a proposal has to be approved by both the Commission and the Council, whatever voting rule the Council has to use to reach a collective decision. If the Commission does not belong to a coalition, then this coalition is not a winning coalition. So, both players can be regarded as necessary players. Therefore, one would expect that both actors have power values of $1 / 2$, and not $1 / 6$ for the Commission and 5/6 for the Council. The bias as revealed by these numbers leads to an exaggeration of the Council's abilities and an understatement of the power of the Commission. In addition, the power value for the Council in a game with the Commission is independent of the number of Council members. The individual values are only relevant to assess each member's power in shaping a Council decision and not a

5 Even if we focus on the individual scores, which suggest that the Commission is as 'powerful' as the Council members, the values do not reveal the Commission's power to shape the final outcome by making the initial proposal. 
decision that has to be taken by several 'institutional' actors, including composite decision making bodies.

This computational method of adding together individual scores is rooted in the notion that the preferences of voters are 'homogeneous' in the sense that the probabilities of voting for a proposal are the same for all voters in a committee. If the preferences of the group members are homogeneous, reaching a group decision is easy. Frictions (or transaction costs) in internal group decision making can be neglected. However, if the members of a group have substantially different preferences, the group will experience much more difficulty in reaching agreement. Heterogeneity of preferences dramatically reduces the power of a collective body vis-à-vis another decision maker. By assuming homogeneous preferences the traditional voting power indices passes over this problem, which is highly problematic for an analysis of the inter-body division of power in the framework of a weighted voting game.

That is not to say that traditional power indices are unable to take conceptually account of voter's preferences or spatial voting (see Straffin, 1994). ${ }^{6}$ However, this is not done in empirical studies. The calculated power index scores are interpreted as a measure of a priori or average power of voters. Voters are assumed not to know the issues at stake, or the preferences of the players. So, voters do not know which coalitions are more likely to form than others and therefore have to assume equal probability with regard to their occurrence.

Diagram 1 also illustrates the importance of distinguishing 'power' from 'luck'. The equilibrium outcome of the game is $x=C$, that is, the most preferred position of the Commission. This outcome seems

6 In probabilistic characterizations of voting power indices each voter $i$ 's probability $p_{i}$ of voting 'yes' on a proposal is a random variable. Taking the $p_{i}$ as an indicator of the acceptability of a proposal to voter $i$ (see Straffin, 1994: 1137), homogeneous as well as heterogeneous preferences can be modeled. If each $p_{i}$ is chosen independently from the uniform distribution on $[0,1]$ we have the Banzhof index. The independence assumption means that the acceptability of a proposal to voter $i$ is independent of its acceptability to any other voter $j$ (see Straffin, 1994: 1137). Note, that $p_{j}=1 / 2$, which means that voter $j$ voting 'yes' is similar to flipping a coin. Note further, that the probability characterization of the Banzhof index is restricted to its non-normalized version. If the random variable $p$ is chosen from the uniform distribution on $[0,1]$, and $p_{i}=p$ for all $i$ (homogeneity assumption), we have the Shapley-Shubik index. Here the acceptability of a proposal is the same to all voters. 
to be more favorable to Council member 2 than member 5, since the distance to $V_{2}$ is less than the distance to $V_{5}$. Is member 2 therefore also more powerful? Both players have the same abilities to affect the outcome, that is, to veto the Commission proposal. So, from this perspective, there is no difference in power. Nevertheless, the outcome is closer to member 2's preferences. This indicates that member 2 is more 'lucky' than member 5. Having a preference that lies close to the equilibrium outcome of a particular game does not necessarily mean that this player is also 'powerful'. Similarly one may question whether Council member 1 is more 'powerful' than the other Council members, since this player defines the boundary, $V_{I}(q)$, where the Commission can no longer select its ideal point, should this player move to the right. ${ }^{7}$ If the position of this member can also be occupied by any other player, or when the status quo can be located at any other point along the policy dimension, Council member 1 is just more 'lucky' than the others. Following Barry (1980), we regard a player's success, which is defined as the extent to which the outcome of the decision making process corresponds to its ideal point, as the composite effect of 'power' and 'luck'. Part of a player's success is therefore based on 'luck', the other part is due to the 'power' a player exerts. While power can be associated with a player's ability to affect the final outcome, 'luck' is related to the preferences of the other players and the location of the status quo, which are assumed to be exogenously determined. The latter can be illustrated with the role of the Commission in our example of the consultation procedure. The fact that the outcome of the game coincides with the Commission's most preferred point does not imply that the other players in the game are 'powerless'. This result depends on the preferences of the Council members and the location of $q$. A shift of $V_{l}$ to the left may, for instance, force the Commission to propose a policy $x=V_{l}(q)$. So, given the preference configuration, the Commission is 'lucky' that Council members have preferences that allow for the equilibrium outcome $x=C$. This clearly indicates that

7 There is an asymmetry worth mentioning: the boundary where the Commission can no longer select its ideal point, should it move to the right, is independent of the question of who occupies the leftmost position, namely the status quo, $q$. 
the success of a player in a game is the combined result of its abilities and the specific preference configuration. To assess a player's power a measure should be based on the former and not the latter.

\section{A new approach}

\subsection{Players' distances and relative positions}

Our method to evaluate the distribution of power is embedded in the recently developed theory of political institutions, which shows that institutions play an important role in shaping the process of political decision making (see, for instance, Ostrom, 1986; Riker, 1980; Shepsle, 1989; Shepsle and Weingast, 1981). Institutions may determine the extent to which players are enabled to participate in the decision making process. They affect the kind of actions players are allowed to take and the sequence in which players may act. By excluding specific player options, institutions may induce political stability and determine the equilibrium outcome of a game. This notion of institutions forms the basis of the concept of structureinduced equilibrium developed by Shepsle (1979). A structure-induced equilibrium is a stable policy that cannot be defeated or changed by the players, given the decision making rules of the game.

This concept has been widely used to analyze the outcomes of decision making under various legislative institutions. ${ }^{8}$ Mostly, these models point at unique equilibrium outcomes, which can be either the status quo, when one of the players objects to a proposed change, or a new policy, when all players prefer a change. Nevertheless, the current theory of political institutions needs to be developed further. For instance, no equilibrium may be found, which indicates that the predictive power of the theory has to be further improved by either refining current equilibrium concepts or conferring more structure on the decision making process. In this paper we will not discuss these developments further. Rather we shall focus on games for which equilibria exist.

8 See Moser (1997b), for a recent review of this literature. 
We approach power as a player's ability to affect the equilibrium outcome in a game which is defined by a decision making procedure. The stronger a player's influence on the outcome under a specific decision making procedure, the more powerful this player is. This ability to exert influence can take various forms. Some players, such as the Commission in Diagram 1, may be able to propose a policy, while others, like the members of the Council, only have the right to veto a proposal, thereby constraining the initial choice of another player. To distinguish 'power' from 'luck', we propose a measure that is independent of the specific preferences of players, which, together with the decision making procedure, determine the outcome of a game. This can be achieved by measuring a player's power under some decision making procedure with reference to the mean or expected distance between the equilibrium outcome and this player's ideal point for all possible combinations of players' preferences and all possible combinations of the status quo. By focusing on the expected distance the measure will indicate a player's a priori prospects of playing a game without knowing the preference configuration of all players in the game and the location of the status quo. More formally, let $n \in \mathbb{N}$ be the number of players in a game describing a decision making procedure $\pi$. For an $m$-dimensional and finite outcome space $X \subseteq \mathbb{R}^{m}$, these players have Euclidean preferences, which can be characterized by player $i$ 's ideal point $x_{i}=\left(x_{i}^{l}, x_{i}^{2}, \ldots x_{i}^{m}\right)$. Let $q \in X$ denote the status quo, that is, the hypothetical state of affairs before the start of the decision making process. This can be the current policy, or the situation without such a policy. We call a combination of a particular ideal point for each player and the status quo a 'state of the world', which will be denoted as $\xi=\left(x_{1}, x_{2}, \ldots x_{n}, q\right)$. Finally, let $x^{\pi}(\xi)$ be the unique equilibrium outcome of the game based on procedure $\pi$, given the state of the world $\xi$ (that is, given players' preferences and a status quo). ${ }^{9}$

Our measure of power is based on the expected distance between the equilibrium outcome and the

9 At this point we focus on a unique equilibrium outcome only for expositional convenience. The strategic power index can also be applied to games for which multiple equilibria exist. This requires a slight modification, which we describe in note 10. 
player's ideal point for all possible configurations of preferences and the status quo, or states of the world. In this context, each particular state of the world is assumed to be the instance of a random variable $\bar{\xi}=\left(\overline{x_{1}}\right.$, $\left.\bar{x}_{2}, \ldots \overline{x_{n}}, \bar{q}\right)$. The expected or mean distance between the equilibrium outcomes for some decision making procedure, $\pi$, and player $i$ 's ideal point is then given by

$$
\Delta_{i}^{\pi}=\int \delta_{i}^{\pi} f(\bar{\xi}) d(\bar{\xi})
$$

where

$$
\delta_{i}^{\pi}=\sqrt{\sum_{k=1}^{m}\left(x^{\pi}(\bar{\xi})^{k}-\bar{x}_{i}^{k}\right)^{2}}
$$

is the Euclidean distance between the equilibrium outcome of the game and the ideal point of player $i$ in any particular state of the world, and $f(\bar{\xi})$ is the density function if $\bar{\xi}$ is a continuous random variable. ${ }^{10}$ The mean distance as expressed by $\Delta_{i}{ }^{\pi}$ allows us to assess the relative power of different players within a game: all other things being equal, a player is more powerful than another player if the expected distance between the equilibrium outcome and its ideal point is smaller than the expected distance for the other player.

\subsection{Indices: strategic power and inertia}

A comparison of players' abilities over different games requires some standardization of the power

10 If the game does not have a unique equilibrium, but multiple equilibria, the simple Euclidean distance can be replaced by the average Euclidean distance, i.e. the sum of the Euclidean distances between each equilibrium outcome and the player's ideal point for all equilibria in a particular state of the world, divided by the number of equilibria. 
measure. This can be done with reference to a dummy player, that is, a player whose preferences vary over the same range as the preferences of the actual players, but that has no decision making rights in the game. This player's preferences, therefore, do not matter for the outcome of the game. It only experiences some equilibrium outcome that is set by the other players. Sometimes the dummy player is 'lucky' in having an ideal point that is close to the equilibrium outcome. However, the dummy player may also be less fortunate and encounter a policy outcome that is quite different from its most preferred option. Consequently, the mean distance found for this player represents a minimum value that can be associated with a 'powerless' player. The notion of a dummy player allows us to indicate the absolute positions of players in the game. Only players with shorter expected distances can be regarded as 'powerful'. All other players hold symbolic positions in the game in the sense that their decision making rights generally do not affect the equilibrium outcome.

Treating the dummy player, $d$, in a similar way as the actual players (with an ideal point and the corresponding random variable), the expected distance between the dummy player's ideal point and the equilibrium outcome of a particular game based on procedure, $\pi$, can be defined as $\Delta_{d}^{\pi}$. We then define the power of player $i$ as

$$
\Psi_{i}^{\pi}=\frac{\Delta_{d}^{\pi}-\Delta_{i}^{\pi}}{\Delta_{d}^{\pi}}=1-\frac{\Delta_{i}^{\pi}}{\Delta_{d}^{\pi}},
$$

which is called the strategic power index. This index lies in the interval $[0,1]$ and increases with the power of player $i$. The expected distance for a player that is 'powerful' enough to dictate the outcome of a game under any preference configuration would be zero leading to a corresponding value for the index of one. By contrast, if a player has a similar effect on the outcome of a game as the dummy player (which, by 
definition, is 'powerless'), the expected distance for this player is the same as for the dummy player leading to a corresponding value for the index of zero. ${ }^{11}$

Based on this index, there is a natural way to approach the status quo bias of the decision making process, that is, the extent to which players are unable to act and to pull a new policy away from the current state of affairs. For a specific procedure, the status quo bias can be measured by the distance between the equilibrium outcome and the status quo, which is defined as $\Delta_{q}^{\pi}$. Substituting this value for the expected distance found for a player in the strategic power index, we get

$$
\Psi_{q}^{\pi}=\frac{\Delta_{d}^{\pi}-\Delta_{q}^{\pi}}{\Delta_{d}^{\pi}}=1-\frac{\Delta_{q}^{\pi}}{\Delta_{d}^{\pi}},
$$

which is called the inertia index. A value of one for this index means that under some procedure the status quo always prevails. The smaller the value for the index, the more players are able to move the equilibrium policy away from the status quo.

\subsection{Measuring strategic power}

The strategic power and inertia indices are difficult to manipulate analytically, since they are based on the equilibrium outcomes of the underlying policy game. These outcomes may depend on both players' preferences and the status quo in a non-linear way. However, it is relatively simple to calculate such indices numerically, given some assumption about the distribution of individual preferences. Assuming that the set of available policy options is finite, that is, the outcome space $X$ contains a finite number of points, the number of states of the world will be finite, too. More specifically, assume that there are $a$ possible

11 Since the ideal points for each player are independent random variables, the equilibrium outcomes can never be systematically biased against the interest of a particular player, and, therefore, no player can fare worse than the dummy player. Thus, the proposed index can never become negative. 
outcomes. With $n$ actual players, a dummy player, and considering the status quo, there will be $s=a^{n+2}$ possible states of the world $\xi_{1} \ldots \xi_{\mathrm{s}}$. It is then possible to generate a list of all possible states of the world for which equilibrium outcomes can be determined based on a decision making procedure. Subsequently, the expected distance between these outcomes and the ideal points of players can be determined, weighting each particular state of the world with the probability of its occurrence. ${ }^{12}$ We followed this approach in the application of both indices to legislative decision making in the European Union.

\section{Strategic power in the European Union: an application}

\subsection{The decision making procedures}

In our application we focus on the two oldest and most frequently studied procedures for legislative decision making in the Union. The first procedure is the consultation procedure, which is the traditional arrangement for legislation. The second procedure is the cooperation procedure, which was introduced in 1987 by the Single European Act. The main difference between both procedures is that in the latter the European Parliament has the right to reject Council decisions. In this paper we will use the results as presented in Steunenberg (1994) to compute the strategic power index for the main institutional actors in the European Union. $^{13}$

12 For example, if we assume that player preferences are uniformly distributed and, hence, each state of the world has the same probability of occurrence, the expected distance will simply be

$$
\Delta_{i}^{\pi}=\frac{\sum_{j=1}^{s} \delta_{i}^{\pi}}{s} .
$$

13 This study is, as far as we know, the first comparative analysis of decision making procedures in the Union based on non-cooperative game theory. More recent examples include Crombez (1996), Laruelle and Widgrén (1997), and Laruelle (1997). Furthermore, the cooperation procedure has been studied by Tsebelis (1994) and Moser (1997a). 
Steunenberg's model assumes three types of players, viz., the members of the Council, the Commission, which will be regarded as a unitary actor, and the members of the European Parliament. These players have Euclidean preferences and decide on a policy issue that can be represented by a one-dimensional outcome space. In addition, players are assumed to behave as politically sophisticated players and are assumed to have complete and perfect information..$^{14}$ Finally, and most important to our application, legislation in the European Union is approached as a sequential game. Players select their actions in an order that is specified by the decision making procedure used. Set up in this way, the model leads to unique equilibrium outcomes for different preference configurations and locations of the status quo. ${ }^{15}$ Let us now turn to the decision making procedures and the sequences that are used in the model to identify these outcomes for different states of the world.

A legislative process that follows the consultation procedure starts with a proposal by the Commission, which has the exclusive right of initiative. The Commission submits the proposal to the Council, which consults Parliament and advisory boards such as the Economic and Social Committee. After these consultations, the Council will take a decision. At this point two variations of the consultation procedure can be distinguished. The first version, which will be called the 'unanimity' version, always requires a unanimous vote of the Council to adopt or amend the Commission proposal. ${ }^{16}$ The second version allows the Council to approve the initial Commission proposal by a qualified majority. This procedure will be called

14 Two different lines of research can be distinguished in regard to this choice. The first line, which is found in a large number of studies, explores the effects of information asymmetry on decision making (see, for instance, Matthews, 1989; Banks and Weingast, 1992). A second line examines the effects of different institutions on the outcomes of decision making within a framework in which players are assumed to have complete and prefect information. Naturally, a general model of decision making should incorporate both lines of research. Nevertheless, the incorporation of information asymmetries will increase mathematical complexity and require a reduction of institutional features. In face of this tradeoff, we prefer to maintain in the model the complex sequence of moves, which characterizes the Union's decision making process, and thus follow the second line of research.

15 The equilibria identified in Steunenberg's study can be characterized as subgame perfect Nash equilibria.

16 See, for instance, Articles 109(1) and 109f(7) EC, which concern monetary policy (EMU). 
the 'majority' version. ${ }^{17}$ However, if the Council decides to amend the Commission's proposal, a unanimous vote is required, as under the unanimity version.

\section{[Diagram 2 about here]}

The procedure can be modeled as a sequential game with two stages. ${ }^{18}$ In the first stage, the Commission decides whether or not to initiate legislation, and if it does the Commission submits a proposal to the Council. The Council will consider the proposal in the second stage, which can be amended by unanimity. Approval of the proposal can be either by unanimity for the 'unanimity' version or by qualified majority for the 'majority' version of the procedure. Note that Parliament is not included in the model, since it only needs to be consulted by the Council. Parliament does not have any rights to block or change the outcome of Council decision making. ${ }^{19}$ The sequence of this procedure is presented in Diagram 2.

Both games can be solved for the sophisticated voting outcome by using backward induction. Starting with the last stage, and working their way back through the game tree, the players can determine their optimum choices. These equilibria and their outcomes in terms of public policy are presented in

17 See, for instance, Article $94 \mathrm{EC}$, which concerns the regulation of state aid.

18 Steunenberg (1994), who follows an interpretation of the treaty by Kapteyn and VerLoren van Themaat, distinguishes a third stage in his model in which the Commission may consider to veto the Council proposal. Kapteyn and VerLoren van Themaat (1990: 252) suggest that the Commission has the possibility to withdraw a proposal and thus to end the legislative process, which in their view is implicitly based on Article 189a(2) EC. Based on this interpretation, the Commission has the possibility to kill any unfavorable amendment of the Council (as long as the Council has not made a decision). Nevertheless, the Council may ask the Commission to prepare a proposal, which suggests that the Commission cannot continue to block decision making by not taking an initiative. We do not consider this veto possibility. In addition, this stage does not appear to be relevant for the equilibrium outcome, as Steunenberg notes in the Appendix (1994: 664-6), and thus can be omitted for that reason, too.

19 The European Court of Justice ruled that the consultation of Parliament is necessary for the adoption of a proposal. As Corbett, Jacobs and Shackelton (1995: 192-3) note, this ruling gave Parliament the possibility to delay matters by referring proposals back to its committees. Especially for urgent matters, the consultation obligation provides Parliament with a bargaining position in the Union's decision making process, which can be used in an 'opportunistic' manner. Since the model we use does not consider time, we do not deal with this kind of behavior. 
Steunenberg (1994: 664-5). ${ }^{20}$ Based on these results, he shows that under the consultation procedure the

Commission may frequently act as an agenda setter, because Council members may only amend the

Commission's proposal by unanimous consent, which can only be reached in rather exceptional instances.

Consequently, the Commission is able to force the Council to approve a policy that is not the best choice of all of its members, but is more closely located to the preference of the Commission. Parliament, on the other hand, does not affect the equilibrium outcome at all, since, according to this procedure, it only needs to be consulted.

The cooperation procedure, as introduced in the Single European Act, was intended to increase the influence of the European Parliament. Besides the consultation obligation, which allows Parliament to present amendments to the Council proposal, it may reject the Council proposal. The Council, however, has

20 The unique equilibrium outcome, $x^{c o n / u}(\xi)$, for the unanimity version of the consultation procedure, which will be denoted as con/ $u$, can be summarized as follows.

Let $L_{i}$ denote the ideal point of member $i$ of the Council ( $l=$ leftmost member; $r=$ rightmost member; $m=$ median member; $s=$ leftmost decisive qualified majority member; $s^{\prime}=$ rightmost decisive qualified majority member; note that by definition $\left.L_{l} \leq L_{s} \leq L_{m} \leq L_{s^{\prime}} \leq L_{r}\right) ; C$ is the ideal point of the Commission; $L_{i}(q)$ is the indifference point of Council member $i$ to the status quo; and, $C(q)$ is the indifference point of the Commission to $q$.

Assume, for simplicity, that $q \leq L_{m}$. Then:

(1) if $q>L_{l}: x^{c o n / u}=q$;

(2) if $q<L_{l}$ and $q \geq C: x^{c o n / u}=q$;

(3) if $q<L_{l}$ and $q<C$ :

(a) if $C<L_{l}$ : (i) if $C(q)<L_{l}: x^{c o n / u}=q$; (ii) if $C(q) \geq L_{l}: x^{\text {con } / u}=L_{l}$;

(b) if $C \geq L_{l}$ : (i) if $C \leq L_{l}(q): x^{c o n / u}=C$; (ii) if $C>L_{l}(q): x^{c o n / u}=L_{l}(q)$;

Similar results can be derived for the symmetric case of $q \geq L_{m}$.

For the majority version of the procedure, which will be denoted as $c o n / m$, the following unique equilibrium outcomes, $x^{c o n / m}(\xi)$, have been found. Again assume that $q \leq L_{m}$. Then,

(1) if $q \geq L_{s}: x^{c o n / m}=q$;

(2) if $q<L_{s}$ and $q \geq L_{l}$ :

(a) if $q \geq C: x^{c o n / m}=q$;

(b) if $q<C$ : (i) if $C \leq L_{s}(q): x^{c o n / m}=C$; (ii) if $C>L_{s}(q): x^{c o n / m}=L_{s}(q)$;

(3) if $q<L_{l}$ and $q \geq C: x^{c o n / m}=q$;

(4) if $q<L_{l}$ and $q<C$ :

(a) if $C<L_{l}$ : (i) if $C(q)<L_{l}: x^{c o n / m}=q$; (ii) if $C(q) \geq L_{l}: x^{c o n / m}=L_{l}$;

(b) if $C \geq L_{l}$ : (i) if $C \leq L_{s}(q): x^{c o n / m}=C$; (ii) if $C>L_{s}(q): x^{c o n / m}=L_{s}(q)$.

Similar results can be derived for the symmetric case of $q \geq L_{m}$. 
the possibility to override a veto by Parliament, which requires unanimous consent among Council members. The procedure follows the first two stages of the consultation procedure and can be modeled as a sequential game with four stages. ${ }^{21}$ After a Commission proposal, $x$, in the first stage, the Council determines its common position, $y$, in the second stage. This position can be the Commission's proposal, which has to be approved by a qualified majority, or an amended proposal based on a unanimous vote. In the third stage the European Parliament decides whether or not it will veto the common position. A veto requires an absolute majority. If a majority in Parliament disagrees with $y$ and rejects the common position, the Council may override the veto by unanimity in the fourth stage. If the Council succeeds, its proposal can be enacted as law. Otherwise, the status quo will prevail. The sequence of this procedure is presented in Diagram $3 .^{22}$

\section{[Diagram 3 about here]}

21 Tsebelis (1994) shows that the European Parliament may have 'conditional agenda setting' power under the cooperation procedure. However, the Commission does not play a role in Tsebelis' formal model (see his appendix). For this reason, Moser (1996) criticized Tsebelis' analysis and shows how the results may change when the Commission takes the lead in shaping the common position. He concludes that Parliament only has conditional veto rights. The core of their dispute is about the Commission's role in the first reading of the procedure. Using the sequence of the decision making process as laid down in the Treaty, we follow Steunenberg's modeling of the role of the Commission, except for the point mentioned in note 18 .

22 See Steunenberg (1994: 665-6) for the formal results for this procedure, which can be summarized as follows. Let $P$ denote the ideal point of the median member of Parliament (see note 20 for additional notation). Furthermore, let coop denote the cooperation procedure. Assume, for simplicity, that $q \leq L_{m}$. Then:

(1) if $q \geq L_{s}: x^{\text {coop }}=q$;

(2) if $q<L_{s}$ and $q \geq L_{l}$ :

(a) if $q \geq C: x^{\text {coop }}=q$;

(b) if $q<C$ : (i) if $q \geq P$ : $x^{\text {coop }}=q$; (ii) if $q<P$ : (1) if $C \leq \min \left\{L_{s}(q), P(q)\right\}: x^{\text {coop }}=C$; (2) if $C>$ $\min \left\{L_{s}(q), P(q)\right\}: x^{\text {coop }}=\min \left\{L_{s}(q), P(q)\right\}$;

(3) if $q<L_{l}$ and $q \geq C: x^{\text {coop }}=q$;

(4) if $q<L_{l}$ and $q<C$ :

(a) if $C<L_{l}$ : (i) if $C(q)<L_{l}: x^{\text {coop }}=q$; (ii) if $C(q) \geq L_{l}: x^{\text {coop }}=L_{l}$;

(b) if $C \geq L_{l}$ : (i) if $q \geq P: x^{\text {coop }}=q$; (ii) if $q<P$ : (1) if $P \leq L_{l}: x^{\text {coop }}=\min \left\{C, L_{l}(q)\right\}$; (2) if $P>L_{i}$ : (a) if $C \leq \min \left\{L_{s}(q), P(q)\right\}: x^{\text {coop }}=C$; (b) if $C>\min \left\{L_{s}(q), P(q)\right\}: x^{\text {coop }}=\min \left\{L_{s}(q), P(q)\right\}$;

Similar results can be derived for the symmetric case of $q \geq L_{m}$. 
Based on the equilibrium policies, Steunenberg (1994: 654) concludes that the cooperation procedure leads to a shift in power in favor of Parliament. Parliament may limit (at least in some cases) the agendasetting power of the Commission by threatening to veto the proposed policy. In addition, the procedure may reduce the influence of the Commission on the final outcome, since in formulating its proposal the Commission has to take into account the possibility of an unfavorable majority in Parliament, besides rejection by the Council. ${ }^{23}$ Finally, the procedure is more sensitive to gridlock than the majority version of the consultation procedure. A case of gridlock, typical of the cooperation procedure, occurs when the European Parliament prefers a policy change opposite to that preferred by the Commission or the Council, while a veto of Parliament cannot be overridden by a divided Council.

\subsection{Comparative analysis of strategic power}

Following the approach as suggested in Section 3.3, we calculated the strategic power index for the players in the consultation and the cooperation procedures. For these computations we assumed an outcome space with eight possible outcomes. Based on this space, each player in the game has the possibility to hold a unique most preferred position, which does not coincide with the position of another player and the status quo. Analytically, this space is sufficient to account for the different equilibria that have been identified for the different decision making procedures. A more extensive outcome space may only further increase the mean distances that will be found for the various players. From an empirical point of view, however, our simulations do not reflect the diversity that may occur in reality. More diversity may have an impact on the

23 Moser (1997a) shows that these conclusions remain unaffected when one moves from a single policy dimension to a more dimensional space. He concludes that '...if preferences and status quo remain constant during the decision process, the EP's right to propose amendments is without impact' (Moser, 1997a: 342). As noted before, Moser's modeling differs from Tsebelis' representation of the cooperation procedure concerning the role of the Commission. In Tsebelis' model (1994), the introduction of a second dimension may increase Parliament's ability to select a more preferred amendment, which will be accepted by a qualified majority in the Council. 
absolute magnitude of our index, which therefore needs to be carefully interpreted. ${ }^{24}$

Besides the Commission and the median member of Parliament, we distinguished five members in the Council. This number is sufficient to distinguish between the voting rules that are used by the Council. ${ }^{25}$ Together with a dummy player and the status quo, this leads to $8^{9}$ or 134.2 million different states of the world, which are assumed to be equally probable. ${ }^{26}$ For each of these states of the world, we have determined the ideal point of the most extreme, the decisive and the median Council member and, based on this information, derived the equilibrium outcome of the games defined by each of the three procedures and the particular state of the world. Based on the mean distances between these outcomes and the ideal point of each player, we then calculated the strategic power index. The results are presented in Table 1.

[Table 1 about here]

The table contains the strategic power indices for the Commission, (the median member of) Parliament, and the members in the Council. Based on our index and the underlying model of the decision making process, the Commission appears to be the most powerful player in the consultation procedure and the cooperation procedure. ${ }^{27}$ Since the European Parliament is not formally involved in either consultation procedure, the median member of Parliament has a value of zero: it cannot exercise any influence on the

24 Based on other and smaller numbers, we noted a clear convergence of the values for the index. Nevertheless, there might still exist some 'bias', which is a result of the limited outcome space. However, since we compare the index for different players over different procedures, which are all based on the same number of different states of the world, this 'bias' will be the same for all players and procedures, and therefore does not affect our conclusions.

25 The analysis can be further extended by assuming unequal voting weights for the various Council members, which would allow us to differentiate in power positions between different Council members.

26 Note that traditional voting power indices are based on the assumption that all coalitions are equally probable. The intuition for our assumption is that we are interested in the logic of legislative procedures and do not discuss a specific policy issue. That is the reason why we cannot identify any bias in the probability distribution. If there is no reason to distribute probability mass unevenly, it seems reasonable to assume that preference configurations are uniformly distributed.

27 This is in line with the earlier conclusion of Steunenberg (1994: 651) that, based on the expected outcomes, the Council can hardly be called the 'ultimate locus of Community decision making' with regard to the shaping of public policy. 
outcome of the decision making process. Under the cooperation procedure, the power of Parliament is greater, but of the same magnitude as the power of the member states in the Council. The power of the Commission, however, is greater.

A comparison of the power scores between the two different versions of consultation procedure shows that both the Council members and the Commission would gain power if they were to shift from the unanimity to the majority version of this procedure. However, the Commission gains relatively more. Moving from the majority version of the consultation procedure to the cooperation procedure would reduce the power of the Council members. The same holds for the Commission. The opposite holds for changes from the unanimity version of the consultation procedure to the cooperation procedure.

We also computed the inertia index for the different procedures. The results are presented in Table 2. This index helps to explain why a procedural change, such as a shift from the unanimity to the majority version of the consultation procedure, may give more power to all players. If a procedure always (or almost always) ends in gridlock, then none of the players has the ability to affect the outcome. Procedures that reduce the chance of gridlock may open up the scope for shaping a proposal that is more preferred than the status quo, which will make all players more powerful.

\section{[Table 2 about here]}

The value of the inertia index is highest for the unanimity version of the consultation procedure, where all Council members have to support a policy change. This suggests that this procedure is most sensitive to legislative gridlock. The lowest value is found for the majority version of the consultation procedure, where a qualified majority is sufficient for the passing of a proposal. The cooperation procedure has a slightly higher value, since it allows Parliament to block legislation even if both the Council and the Commission 
agree to a proposal. ${ }^{28}$ In addition, the values of the strategic power index presented in Table 1 are relatively small compared to the values of the inertia index. This suggests that in most states of the world players are not able to agree on a policy change and therefore will maintain the status quo.

28 This is in line with Steunenberg's (1994: 654) observation that Parliament's veto power increases the number of cases of 'non-decision making' or legislative deadlock under the cooperation procedure compared to the majority version of the consultation procedure. 


\subsection{Evaluation of the results: the strategic power index versus voting power indices}

Voting power indices have been used to analyze the distribution of power between different decision making bodies. However, as indicated earlier, these studies do not consider the preferences of the players, and they neglect the more complex institutional structure of the decision making process. As far as we know, there is only one example that deals with decision making in the Union as a sequential process, namely the study by Laruelle and Widgrén (1997). They start by modeling the decision making procedures as extensive form games, but then reduce these sequential games into a sequence of cooperative voting games.

\section{[Table 3 about here]}

Table 3 summarizes the results found for the strategic power index, which we discussed in the preceding section, and three other studies on the inter-body division of power in the European Union that use voting power indices. Besides Laruelle and Widgrén (1997), these are the studies of Berg and Lane (1997), and Turnovec (1997).

The values presented by Berg and Lane (1997) are normalized Banzhaf scores. Based on these values they suggest that the Commission is the 'single most powerful player' in the consultation procedure, but that the Commission does not dominate the Council since "each of the large member states can swing almost about as many times as the Commission' (Berg and Lane, 1997: 13). In addition, the Commission and the member states have less power under the cooperation procedure compared to the consultation procedure, while the Commission and Parliament appear to be equally powerful. Although the Commission and Parliament are slightly more powerful than the largest states in the Council, Berg and Lane (1997: 14) argue that the Council is much more powerful than both other institutional actors. ${ }^{29}$

29 Berg and Lane (1997) also calculate Shapley-Shubik indices. The pattern based on these indices is very similar to that found for the normalized Banzhaf index. However, the values for the Commission as a single actor are higher: nearly $25 \%$ for the consultation procedure, and $20 \%$ for the cooperation proce- 
Although Turnovec (1997) does not explicitly deal with the specific legislative procedures that are used in the Union, his games can be understood as interpretations of the consultation and cooperation procedures..$^{30}$ In Table 3 we included the normalized Banzhaf scores from Turnovec's study. The pattern of these scores is very similar to that found in the two previous studies, with one exception: Parliament exerts more power than the Commission in the cooperation procedure.

Both Berg and Lane (1997) and Turnovec (1997) calculate the power of the Council by adding up the power scores of all Council members. This computational method is highly problematic, as explained in Section 2, since it exaggerates the power of a composite body such as the Council. In addition, it is not very useful to compare the scores found for the individual Council members reported by Berg and Lane, and Turnovec, to the values found for the strategic power index. Berg and Lane as well as Turnovec treat all Council members, the Commission and Parliament as voters in a hypothetical committee, who all have the same probability of voting for a proposal. We base our scores on the strategic interactions between these players for all possible preference configurations. While these individual values are sometimes of the same magnitude, we cannot exclude that the strategic power index leads to different results in other instances, since our index is based on a different approach to power.

The values taken from Laruelle and Widgrén (1997) are based on a non-normalized probabilistic (Banzhaf) power index. They calculate power as the weighted sum of indices found for different periods of the game. They represent a player's power as the average probability that its vote is decisive. The scores reported here refer to a version in which players probabilities of accepting a proposal are independent. In

dure.

30 In the Council-Commission game a proposal is accepted if it is approved by Commission and by a qualified majority of the Council (representation of the consultation procedure). In the CommissionCouncil-Parliament game a proposal is accepted if it is approved by the Commission, by a qualified majority of the Council, and by simple majority in Parliament (representation of the cooperation procedure). 
addition, they account for a 'procedural' status quo bias, which means that the authors allow the decision making process to end without a decision being reached. ${ }^{31}$ We refer to such cases as legislative gridlock, which forms the basis of our inertia index. The results of Laruelle and Widgrén lead to similar observations to those reported by Berg and Lane. ${ }^{32}$ The Council wields more power than the other two institutional actors. Furthermore, the Commission and Parliament are equally powerful under the cooperation procedure. The Council has lost some of its power in favor of Parliament by the introduction of this procedure.

Laruelle and Widgrén also present a version in which they based the Commission's choice to start a legislative process on a random variable. This leads to rather different results in the sense that the Commission becomes more powerful than the Council in both procedures. ${ }^{33}$ However, their approach to agenda setting power does not reflect the strategic considerations that are typical for the behavior of such a player in sequential games. Allowing the Commission to open its gates randomly passes over its abilities to shape policy.

A comparison of these results with the values found for the strategic power index reveals some interesting differences. Based on their findings, Berg and Lane, and Turnovec, conclude that the Council is much more powerful than the Commission. The strategic power index based on Steunenberg's model, however, points at the Commission as the dominant actor. In addition, the Council members now appear to be slightly less powerful as (the median member of) Parliament in the cooperation procedure. Berg and

31 In the case reported here the probability of passing a randomly chosen proposal is $4 \%$ for the consultation procedure and $2 \%$ for the cooperation procedure. The status quo 'bias' is the complement of the probabilities mentioned above (Laruelle and Widgrén, 1997: 19).

32 The figures reported by Laruelle and Widgrén (1997) are small. This is due to the assumption that all players have independent probabilities of accepting a proposal. All scores increase with correlation within the Council, which means that all Ministers have the same probability of accepting a proposal at one period. However, the pattern of the scores remains the same. The same holds for inter-organ correlation, i.e. all organs have the same probability of accepting a proposal at one period.

33 The power values are 0.50 for the Commission for both procedures, and 0.049 and 0.003 for the Council in the consultation and the cooperation procedure, respectively. The European Parliament, which only plays a role in the cooperation procedure, has a value close to zero. 
Lane, and Laruelle and Widgrén, on the other hand, indicate that the Commission has the same power as Parliament. Turnovec's study suggests that Parliament is even more powerful than the Commission, while the Council remains the dominant player.

According to Berg and Lane, Laruelle and Widgrén, and Turnovec, all players lose power in favor of the European Parliament when moving from the consultation procedure to the cooperation procedure. This result can be affected by the constant-sum assumption of their index, as mentioned in the introduction. We find no support for this observation. For the Commission as well as the Council the results are mixed, depending on the relevant version of the consultation procedure: for the unanimity version both players gain power when moving to the cooperation procedure; for the majority version, they both lose power.

\section{Conclusions}

In this paper we have presented a new method for evaluating the distribution of power in policy games. In contrast to voting power indices, which are based on the theory of simple games, the new approach is based on a modeling of decision making processes as a spatial and sequential game. Varying the preferences of the players, we consider the mean or expected distance between the equilibrium outcome and the ideal point of a players as a proxy for their power. Focusing on equilibrium outcomes, the proposed method avoids two drawbacks of the traditional approach based on voting power indices, which neglects the preferences of players on concrete political issues and the more complex institutional structure of the decision making process. Most legislative institutions employ decision making rules that contain more than only a rule for aggregating votes.

The strategic power index as proposed in this paper refers to the ability of a player to make a difference in the outcome of a policy game. This index has many desirable features. First, the proposed index can be based on a careful and detailed analysis of some decision making process in which all relevant institutional 
complexities are taken into account. Second, like the voting power indices, the strategic power index measures a priori power. Third, the index levels outs the effect of 'luck' or a particular preference configuration on the outcome of a game, since it is based on mean distances. Finally, the index measures power in absolute terms, since it relates the position of a player in a game to a dummy player, which is by definition 'powerless'.

The equilibrium outcomes, which are used to compute distances for the power index, can be based on various specifications of spatial models of decision making. In this paper we have presented an example of a sequential game of complete information, which represents the decision making process in the European Union under the consultation and the cooperation procedure. Nevertheless, alternative specifications of these procedures might be conceivable. For instance, the model employed in this paper is based on a single policy dimension, which may describe some of the well-defined policy issues discussed in the Council of the European Union. Enlarging the outcome space to two or more dimensions will show how the balance of power will be affected by more complex issues. Second, players may not be completely informed about the preferences of the other players at some stage of the game. Third, opportunistic behavior can be added to a model, which may shed some light on the role of the European Parliament in the consultation procedure. Finally, in the model the decision making process in the Council, in which the presidency plays an important role, can be further refined by adding more stages to the game. These modifications of the game may affect the values of the index for the players, since they reflect differences in power as a result of these changes. However, these modifications of the model on the decision making process do not affect the proposed index itself.

Since we do not yet know what specification reflects the Union's decision making process best, we are cautious to draw any substantial conclusions based on our analysis. At this point, further empirical research is necessary to sift different models according to their predictive abilities. Nevertheless, at the same time, it 
is evident that the results based on voting power indices do not reflect the current balance of power in the Union. In this paper we have shown the limitations of this approach and presented an alternative conceptualization of power. According to studies using voting power indices (Berg and Lane, 1997; Laruelle and Widgrén, 1997; Turnovec, 1997), the Council is the dominant player in the Union's legislative process. The values found for the strategic power index, as presented in this paper, do not support this view. Depending on the specification of the game, the Council is not the dominant actor, and the Commission may be more important in the shaping of policy. Institutional characteristics, such as the sequence of play and the decision making rights of the individual actors, matter in the Union's decision making process. 


\section{References}

Banks, J.S. and B.R. Weingast (1992) 'The political control of bureaucracies under asymmetric information', American Journal of Political Science 36: 509-24.

Banzhaf, J.F. (1965) 'Weighted voting doesn't work: A mathematical analysis', Rutgers Law Review 19: $317-43$.

Barry, B. (1980) 'Is it better to be powerful or lucky. Part I and Part II', Political Studies 28: 183-194 and 338-52.

Berg, S, R. Maeland, H. Stenlund, and J.-E Lane (1993) 'Politics, economics and the measurement of power', Scandinavian Political Studies 16, 251-68

Berg, S. and J.-E. Lane (1996) Game theory, power, and the European Community. In: M. Wiberg (ed.) Multidisciplinary Views on Strategic Interactions. Turku, Finland: University of Turku Studies on Political Science no 14. 17-34.

Berg, S. and J.-E Lane (1997) Measurements of voting power: Individual and collective properties with applications to the EU. Paper prepared for delivery at the 1997 Annual Meeting of the American Political Science Association, Washington DC, August 28-31, 1997.

Bindseil, U. and C. Hantke (1997) 'The power distribution in decision making among EU member states', European Journal of Political Economy 13: 171-85.

Brams, S.J. (1975) Game theory and politics. New York: The Free Press.

Brams, S.J. (1985) Rational politics. Washington: Congressional Quarterly Press.

Brams, S.J. (1989) Are the two houses of Congress really coequal? In: B. Grofman and D. Wittman (eds) The Federalist Papers and the new institutionalism. New York: Agathon Press. 125-41.

Brams, S.J. and P.J. Affuso (1985) 'New paradoxes of voting power on the EC Council of Ministers', Electoral Studies 4: 135-9.

Brams, S.J., P.J. Affuso, and D.M. Kilgour (1989) Presidential power: a game-theoretical analysis. In: P. Brace, C.B. Harrington, and G. King (eds) The presidency in American politics. New York: New York University Press.

Brams, S.J., A.E. Doherty, and M.L. Weidner (1991) Game theory and multilateral negotiations: the Single European Act and the Uruguay Round. New York: New York University. Economic research report 9145.

Colomer, J.M. (1998) Measuring power in real committees and parliaments. In: M.J. Holler and G. Owen 
(eds) Power indices and coalition formation. Dordrecht: Kluwer.

Colomer, J.M. and M.O. Hosli (1997) Decision-making in the European Union: The power of political parties. Paper prepared for delivery at the 1997 Annual Meeting of the American Political Science Association, Washington DC, August 28-31, 1997.

Corbett, R., F. Jacobs and M. Shackleton (1995) The European Parliament. London: Cartermill (third edition).

Crombez, C. (1996) 'Legislative procedures in the European Community', British Journal of Political Science 26: 199-228

Deegan, J. and E.W. Packel (1979) 'A new index of power for simple $n$-person games', International Journal of Game Theory 7: 113-23.

Fowler, L.L., Polhuis, P.L., and S.C. Paine (1983) 'Changing patterns of voting strength in the European Parliament', Comparative Politics 15: 159-75.

Garrett, G. and G. Tsebelis (1996) 'An institutional critique of intergovernmentalism', International Organization 50: 269-99.

Holler, M.J. (1982) 'Forming coalition and measuring voting power', Political Studies 30: 262-271.

Holler, M.J. (1984) A public good power index. In: M.J. Holler (ed.) Coalitions and collective action. Würzburg: Physica Verlag. 51-9.

Hosli, M.O. (1993) 'Admission of European Free Trade Association states to the European Community: effects on voting power in the European Community Council of Ministers', International Organization 47: 629-43.

Hosli, M.O. (1994) 'Der potentielle einfluß der Schweiz im EG-Ministerrat: eine analyse aufgrund des Banzhaf-machtindexes', Swiss Journal of Economics and Statistics 130: 89-105.

Hosli, M.O. (1995) 'The balance between small and large: effects of a double majority system on voting power in the European Union', International Studies Quarterly 39: 352-70.

Hosli, M.O. (1997) 'Voting strength in the European Parliament: The influence of national and of partisan actors', European Journal of Political Research 31: 351-66.

Johnston, R.J. (1978) 'On the measurement of power: Some reactions to Laver', Environment and Planning 10: $907-14$.

Johnston, R.J. (1995) 'The conflict over qualified majority voting in the European Union Council of Ministers: An analysis of the UK negotiating stance using power indices', British Journal of Political Science 25: 245-54. 
Johnston, R.J. and A.J. Hunt (1977) 'Voting power in the E.E.C.'s Council of Ministers: an essay on method in political geography', Geoforum 8(1): 1-9.

Kapteyn, P.J.G. and P. VerLoren van Themaat (1990) Introduction to the law of the European Communities: After the coming into force of the Single European Act. Deventer: Kluwer.

Kirman, A. and M. Widgrén (1995) 'European economic decision-making policy: Progress or paralysis?', Economic Policy 21: 423-60.

Laruelle, A. (1997) The EU decision-making procedures: Some insight from non cooperative game theory. Louvain-la-Neuve: IRES. mimeo.

Laruelle, A. and M. Widgrén (1997) Voting power in a sequence of cooperative games: The case of the EU procedures. Louvain-la-Neuve: IRES. mimeo.

Lane, J.-E. and R. Maeland (1995) 'Voting power under the EU Constitution', Journal of Theoretical Politics 7: 223-30.

Lane, J.-E., R. Maeland, and S. Berg (1995) 'The EU parliament: seats, states and political parties', Journal of Theoretical Politics 7: 395-400.

Lane, J.-E., R. Maeland, and S. Berg (1996) Voting Power under the EU constitution. In: S.S. Andersen and K.A. Eliassen (eds) The European Union: How democratic is it? London: Sage. 165-86.

Mattei, A. (1990) Pouvior politique et pouvoir economique: la Suisse et l'Europe. Lausanne: Université de Laussanne. Cahiers de recherches économiques no. 9017.

Matthews, S.A. (1989) 'Veto threats: Rhetoric in a bargaining game', Quarterly Journal of Economics 104: 347-69.

Miller, D.R. (1973) 'A Shapley value analysis of the proposed Canadian constitutional amendment scheme', Canadian Journal of Political Science 6: 140-3.

Moser, P. (1996) 'The European Parliament as a conditional agenda setter: What are the conditions? A Critique of Tsebelis (1994)', American Political Science Review 90: 834-8.

Moser, P. (1997a) 'A theory of the conditional influence of the European Parliament in the cooperation procedure', Public Choice 91: 333-50.

Moser, P. (1997b) Legislative institutions and their impact on public policy: A survey. St. Gallen: University of St. Gallen. Discussion paper no. 9708.

Nurmi, H. and T. Meskanen (1996) A priori power measures and the institutions of the European Union. Turku: University of Turku. mimeo.

Nurmi, H., T. Meskanen, and A. Pajala (1996) Calculus of consent in the EU Council of Ministers. Turku: 
University of Turku. mimeo.

Ostrom, E. (1986) 'An agenda for the study of institutions', Public Choice 48: 3-25.

Peters, T. (1996) 'Voting power after the enlargement and options for decision making in the European Union', Aussenwirtschaft 51: 223-43.

Riker, W.H. (1980) 'Implications from the disequilibrium of majority rule for the study of institutions', American Political Science Review 74: 432-47.

Romer, T. and H. Rosenthal (1978) 'Political resource allocation, controlled agendas, and the status quo', Public Choice 33: 27-43.

Romer, T. and H. Rosenthal (1979) 'Bureaucrats versus voters: On the political economy of resource allocation by direct democracy', Quarterly Journal of Economics 93: 561-87.

Shapley, L.S. (1953) A value for n-person games. In: H.W. Kuhn and A.W. Tucker (eds) Contributions to the theory of games, volume II. Princeton: Princeton University Press.

Shapley, L.S. and M. Shubik (1954) 'A method for evaluating the distribution of power in a committee system', American Political Science Review 48: 787-92.

Shepsle, K.A. (1979) 'Institutional arrangements and equilibrium in multidimensional voting models', American Journal of Political Science 23: 27-60.

Shepsle, K.A. (1989) 'Studying institutions: Some lessons from the rational choice approach', Journal of Theoretical Politics 1: 131-47.

Shepsle, K.A. and Weingast, B.R. (1981) 'Structure-induced equilibrium and legislative choice', Public Choice 37: 503-19.

Steunenberg, B. (1994) 'Decision making under different institutional arrangements: Legislation by the European Community', Journal of Theoretical and Institutional Economics 150: 642-69.

Steunenberg, B. (1996) 'Agent discretion, regulatory policymaking, and different institutional arrangements', Public Choice 86: 309-39.

Steunenberg, B., C. Koboldt, and D. Schmidtchen (1995) Policymaking, comitology, and the balance of power in the European Union. Saarbrücken: Center for the Study of Law and Economics. Discussion paper No. 9504.

Steunenberg, B., C. Koboldt, and D. Schmidtchen (1996) 'Policymaking, comitology, and the balance of power in the European Union', International Review of Law and Economics 16: 329-44.

Steunenberg, B., C. Koboldt, and D. Schmidtchen (1997) 'Beyond comitology: European policymaking with parliamentary involvement', Aussenwirtschaft 52: 87-112. 
Straffin, P.D. (1994) Power and stability in politics. In: R. J. Aumann and S. Hart (eds) Handbook of game theory with economic applications, Volume II. Amsterdam: Elsevier. 1127-51.

Taylor, P.J. and R.J. Johnston (1978) 'Population distributions and political power in the European Parliament', Regional Studies 12: 61-8.

Tsebelis, G. (1994) 'The power of the European Parliament as a conditional agenda setter', American Political Science Review 88: 128-42.

Tsebelis, G. (1996) 'More on the European Parliament as a conditional agenda setter: Response to Moser', American Political Science Review 90: 839-44.

Tsebelis, G. and G. Garrett (1997) Why power indices cannot explain decisionmaking in the European Union. In: D. Schmidtchen and R. Cooter (eds) Constitutional law and economics of the European Union. Cheltenham: Edward Elgar. 11-31.

Turnovec, F. (1997) Decision making games in the European Union. Center for Economic Research and Graduate Education of Charles University. mimeo.

Widgrén, M. (1994) 'Voting power in the EC decision making and the consequences of two different enlargements', European Economic Review 38: 1153-70. 
Diagram 1: Preferences of the Commission and the Council members

left

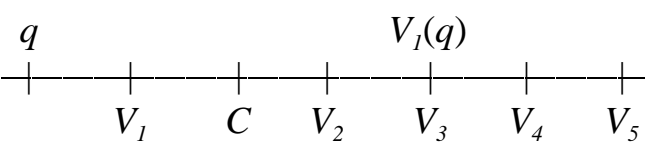

right 
Diagram 2: The sequence of the consultation procedure

\section{a. unanimity version}

stage:

1: Commission

2: Council

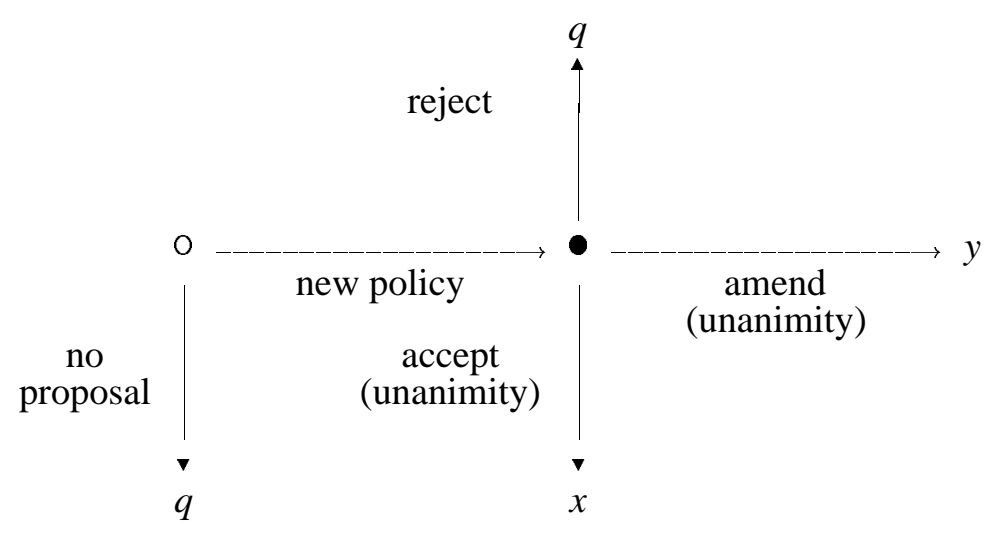

\section{b. majority version}

stage:

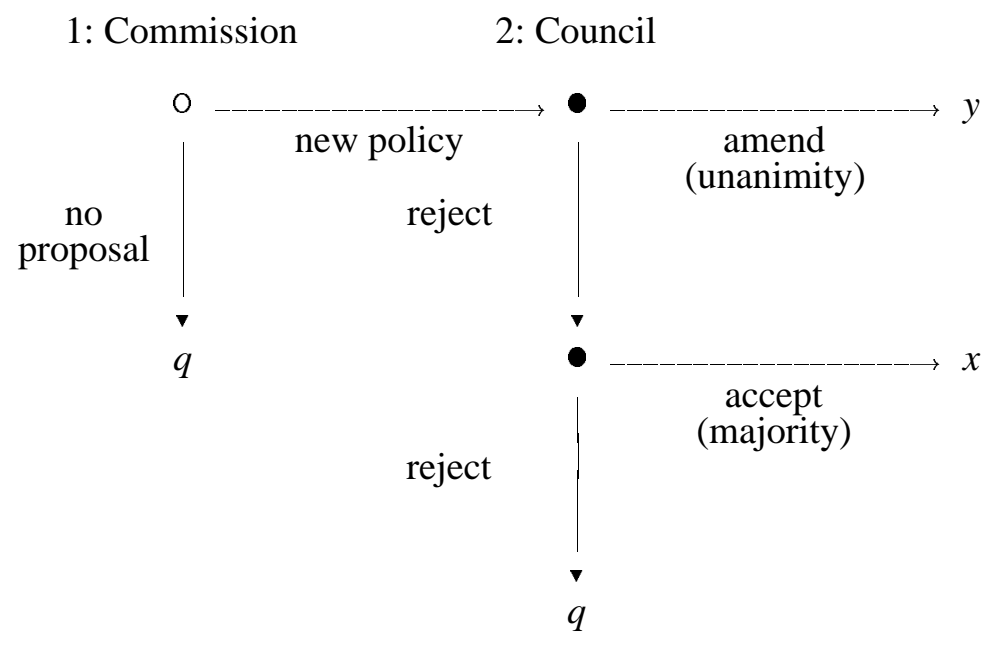

Key to the diagram: $q=$ status quo;

$x=$ Commission proposal;

$y=$ Council policy. 
Diagram 3: The sequence of the cooperation procedure

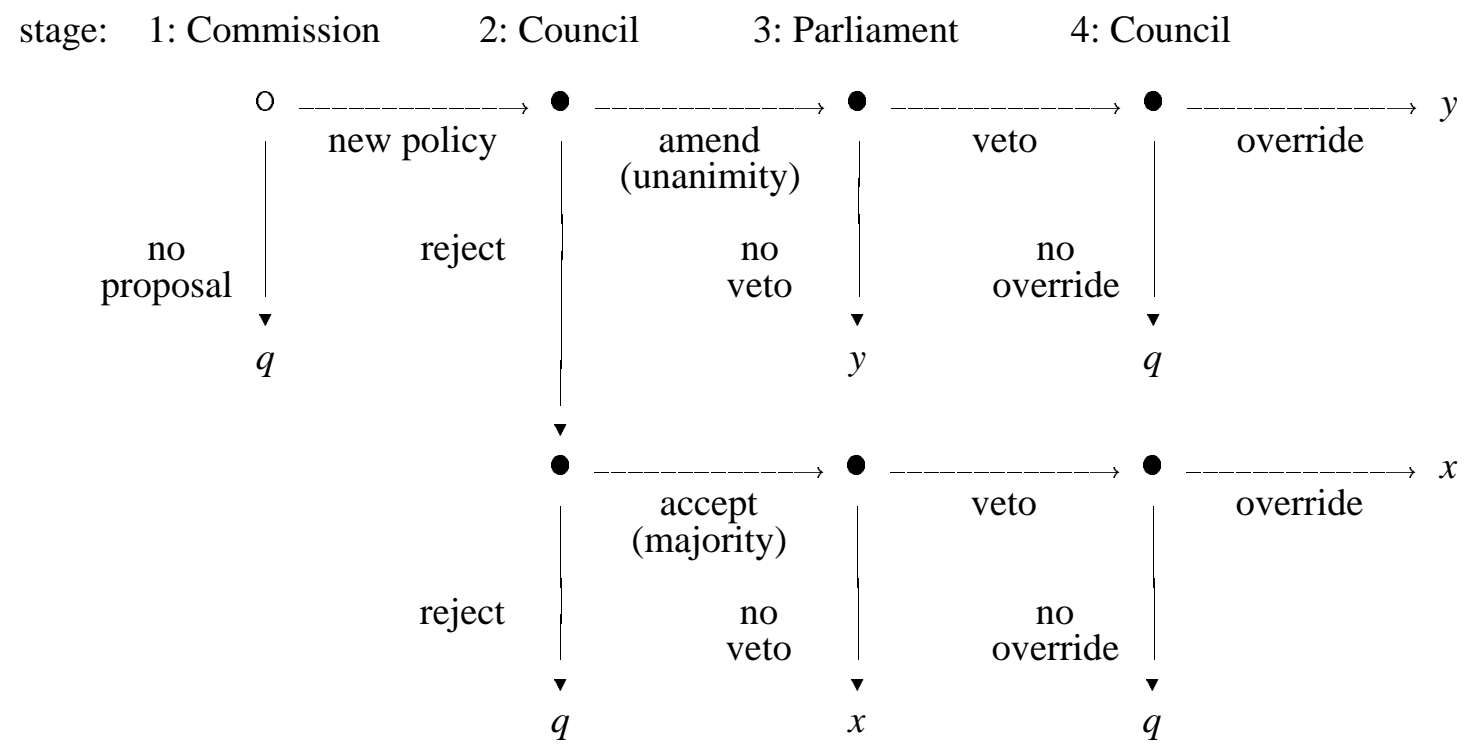

\footnotetext{
Key to the diagram: $\quad q=$ status quo;

$x=$ Commission proposal;

$y=$ Council policy.
} 
Table 1: The distribution of power between the Council, the Commission, and Parliament: the strategic power index for different legislative procedures

player: Council Commission Parliament dummy player

procedure:

$\begin{array}{llcccc}\text { - } & \text { consultation: unanimity } & 0.07 & 0.10 & 0 & 0 \\ \text { - } & \text { consultation: majority } & 0.11 & 0.35 & 0 & 0 \\ \text { - } & \text { cooperation } & 0.08 & 0.24 & 0.13 & 0\end{array}$

Table 2: Inertia under different legislative procedures

procedure:

$\begin{array}{lll}\text { - } & \text { consultation: unanimity } & 0.82 \\ \text { - } & \text { consultation: majority } & 0.52 \\ \text { - } & \text { cooperation } & 0.64\end{array}$


Table 3: The inter-body division of power in the European Union

\begin{tabular}{|c|c|c|c|c|c|c|c|c|c|}
\hline & \multicolumn{3}{|c|}{$\begin{array}{l}\text { strategic power } \\
\text { index }\end{array}$} & \multicolumn{2}{|c|}{$\begin{array}{c}\text { Berg and Lane } \\
\text { (1997) }\end{array}$} & \multicolumn{2}{|c|}{ Turnovec (1997) } & \multicolumn{2}{|c|}{$\begin{array}{c}\text { Laruelle and } \\
\text { Widgrén (1997) }\end{array}$} \\
\hline & $\mathrm{con} / \mathrm{u}$ & $\operatorname{con} / \mathrm{m}$ & coop & con & coop & con & coop & con & coop \\
\hline Commission & 0.1 & 0.35 & 0.24 & 0.13 & 0.12 & 0.13 & 0.11 & 0.012 & 0.001 \\
\hline Council & & & & $0.87 *$ & $0.76^{*}$ & $0.87 *$ & $0.69 *$ & 0.099 & 0.005 \\
\hline $\begin{array}{l}\text {-largest } \\
\text { member }\end{array}$ & & & & 0.10 & 0.09 & 0.10 & 0.08 & & \\
\hline $\begin{array}{l}\text {-smallest } \\
\text { member }\end{array}$ & & & & 0.02 & 0.02 & 0.02 & 0.02 & & \\
\hline $\begin{array}{l}\text { Council } \\
\text { member }\end{array}$ & 0.1 & 0.11 & 0.08 & & & & & & \\
\hline $\begin{array}{l}\text { European } \\
\text { Parliament }\end{array}$ & 0 & 0 & 0.13 & 0 & 0.12 & 0 & 0.2 & 0 & 0.001 \\
\hline
\end{tabular}

Key to the table:

con: $\quad$ consultation procedure; $\mathrm{u}=$ unanimity version; $\mathrm{m}=$ majority version; coop: cooperation procedure.

* These numbers are calculated by adding up the scores of all members of the Council (see Turnovec, 1997: 21, 38). These numbers indicate the percentage of cases in which a member of the Council is decisive. Berg and Lane (1997: 14) do not present these numbers themselves but clearly argue along these lines. 